\title{
TAKING A LIFE
}

The BDJ Upfront section includes editorials letters, news, book reviews and interviews.

Please direct your correspondence to

the News Editor, Kate Quinlan at the BDJ,

The Macmillan Building, 4 Crinan Street,

London, N1 9XW or by email to

Stephen Hancocks OBE

k.quinlan@nature.com

Editor-in-Chief

Press releases or articles may be edited,

and should include a colour photograph

if possible.

$\mathrm{S}$ me years ago when I worked for the FDI World Dental Federation the phone rang and an American voice asked if I knew the number of periodontists in Lombardy. 'Thirty seven,' I replied without hesitation. 'That is remarkable', he said, 'do you have names and addresses for them all?' Touché. It was too good an opportunity to pass by because in reality I had no idea how many there were, doubted that anyone would and had to admit as much to the disappointed and somewhat bemused public relations man from Manhattan.

The point was that it should have been perfectly possible for someone, somewhere to have known that, to have counted them and to have recorded it as a matter of fact. By the same token you would think that someone, somewhere could answer the question as to whether or not dentists have a high rate of suicide? Interestingly, frustratingly perhaps, there are a variety of opinions, much speculation and lots of myths but no one seems to know for sure; although there is some recent evidence that it is no longer the case.

Alexander, in a 2001 article, traces the beginnings of the myth to the 1920s when the media repeatedly portrayed dentists as being suicide prone based on studies that lacked the correct scientific weighting for demographics. ${ }^{1}$ Consequently over the years both the medical and dental professions have been referenced as groups of healthcare providers that are at a high risk of committing suicide.

A recent study compared suicide rates across all occupations in Britain, how they have changed over \section{(n)}

\section{'Every life lost before it needs to be is a sadness to us all'}

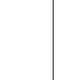

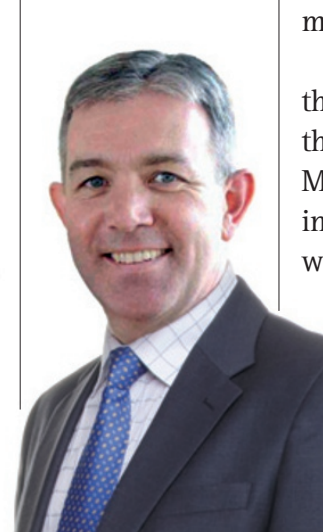

the past 30 years, and how they may vary by occupational socio-economic group. ${ }^{2}$ The authors found that several occupations with the highest suicide rates during 1979-1980 and 1982-1983, including veterinarians (ranked first), pharmacists (fourth), dentists (sixth), doctors (tenth) and farmers (thirteenth), have easy occupational access to a method of suicide (pharmaceuticals or guns). By 2001-2005, there had been large significant reductions in suicide rates for each of these occupations, so that none ranked in the top 30 occupations. Occupations with significant increases in suicide rates over time were all manual whereas those with suicide rates that decreased were mainly professional or non-manual.

Sitting somewhere in between these positions the lyrics of the theme song to the 1970s film $\mathrm{M}^{*} \mathrm{~A}^{*} \mathrm{~S}^{*} \mathrm{H}$, set in a US field hospital in the Korean War, include the words 'suicide is painless, it brings on many changes' and interestingly adds to the mythology by having an army dentist named Captain 'Painless' Woldalski apparently commit suicide aided by his comrades. Suicide is not of course painless, certainly not to those left behind to wonder and to grieve, and our recent article on the issue has prompted letters and emails, most not appropriate for publication, and spawned comment elsewhere with speculation as to the cause of this most distressing circumstance. $^{3}$

This has served to underline the seriousness that we feel as a professional community when a colleague has been driven to end his or her life, possibly as the result of the pressures of a vocation from which, despite it vagaries, the majority of us still manage to gain satisfaction and fulfilment. It has also turned a spotlight on our shared pain and concern for the families, friends and close colleagues who remain and attempt to make sense of the void.

I am not sure that it is helpful to add further speculation here as to the derivation of the motivations. A whole raft of possibilities exist; is it to do with the psychological profile of those attracted to the profession, the financial and bureaucratic pressures of the business model under which some of us find ourselves working, the anxiety absorbed from patients who profess to 'hate' dentists, the gradual decline towards 'burnout' or the socio-economic stresses of material expectations? Every reader can undoubtedly add their own thoughts, theories and factors but crucially each case is individual and is about an individual.

Wherever the truth lies and in particular wherever the cause or causes find their roots it is important that we put in place as many strategies as possible to reduce the stresses of our daily work, identify colleagues at risk and establish methods of support and prevention.

Whether we have the highest or lowest rates every life lost before it needs to be is a sadness to us all. We may not know the number of periodontists in Lombardy but we can make it our business to know more about our fellows in distress.

1. Alexander R E. Stress-related suicide by dentists and other health care workers. Fact or folklore? J Am Dent Assoc 2001; 132: 786-794.

2. Roberts $S E_{1}$ Jaremin $B$, Lloyd K. Psychol Med 2013; 43: 1231-1240.

3. Renshaw J. Dentist suicides. Br Dent J 2013; 215: 593-594.

DOI: 10.1038/sj.bdj.2014.6 